\section{RECEPÇÃO E LEITURA NO \\ HORIZONTE DA LITERATURA}

Regina Zilberman
A recepção, de Aristóteles aos modernos

Matéria que foi objeto de consideração da Teoria da Literatura nas últimas décadas do século XX, a recepção pode reivindicar procedência ilustre e milenar, já que, observada sob o enfoque da longue durée, como a concebe Fernand Braudel, ${ }^{*}$ remonta a Aristóteles e à Poética. Nessa obra, em que define a poesia enquanto mímesis, Aristóteles reconhece que a representação de ações humanas provoca um efeito sobre o público. Esse efeito, a catarse, tem características próprias, facultando ao ser humano experimentar emoçóes intensas, ao mesmo tempo expurgando-as e purificando-se. A catarse é introduzida por Aristóteles no contexto de sua definição de tragédia:

É a tragédia a representação duma ação grave, de alguma extensão e completa, em linguagem exornada, cada parte com o seu atavio adequado, com atores agindo, não narrando, a qual, inspirando pena e temor, opera a catarse própria dessas emoçōes.

$\mathrm{Na}$ tragédia, a mímesis é direta, porque as personagens aparecem por meio das ações - práxis - dos atores; e essas ações inspiram "pena e temor" ou, segundo outra tradução, piedade e terror. Esses sentimentos não são sofridos pelas figuras que se encontram no palco, mas pelos espectadores que ocupam o anfiteatro. Catarse significa, pois, a reação de cada indivíduo que participa da audiência da tragédia, sendo que, para Aristóteles, apenas aquele gênero produz, de modo cabal, tal resultado em seus destinatários.

Aristóteles expõe sua tese em um tempo em que a transmissão da poesia fazia-se por meio da voz, e não da escrita, sendo vivenciada de modo direto. A tragédia duplica esse processo, já que pertence à sua natureza delegar à fala a construção da fábula, sem mediaçōes, como é a do narrador, no caso da epopéia. Por essa razão, a catarse se apresenta de modo pleno, enquanto que nos outros gêneros praticados pelos gregos, a poesia épica, no âmbito da narrativa, ou a comédia, no âmbito do drama, o processo dá-se de modo parcial.

De uma maneira ou de outra, Aristóteles ratifica a importância da recepção para a atribuição do valor de uma obra, já que a
" (BRAUDEL, Fernand. Civilização material, economia e capitalismo. Trad. de Telma Costa. São Paulo: Martins Fontes, 1995. 3v.)

* (ARISTÓTELES. Poética. Em: ARISTÓTELES, HORÁCIO, LONGINO. A poética clássica. Trad. de Jaime Bruna. São Paulo: Cultrix; EDUSP, 1981: 24.)

• (ARISTÓTEles, Poética. Trad. de Eudoro de Sousa. Porto Alegre: Globo, 1966: 74.) 
quantidade (maior na tragédia, menor na comédia e na epopéia) e a qualidade (maior em tragédias bem conduzidas, como Édipo rei, de Sófocles, menor em dramas de final arranjado, como a Medéia, de Eurípedes) de catarse é critério para avaliação dos produtos expostos ao público. Conceito formulado no século IV a.C., a catarse, por sua vez, corresponde também a uma mudança no modo de conceber o trânsito da poesia na sociedade.

Com efeito, entendendo a catarse enquanto a reação de um sujeito quando da assistência a um drama, Aristóteles desvincula a tragédia do universo religioso em que esse gênero foi gestado. Assim, o filósofo compreende a poesia em geral, e a tragédia em particular, dentro de uma perspectiva profana, o que repercute sobre sua circulação, não mais dependente dos aparatos de culto, de uma parte, e das iniciativas políticas, de outro, a que aquelas formas artísticas estiveram subordinadas durante o século $\mathrm{V}$ a.C. Ainda que de modo indireto, Aristóteles registra a secularização da poesia, fundamental para sua expansão e fortalecimento de modo autônomo já na Antigüidade, secularização que, frise-se, deriva do reconhecimento da ação da platéia, traduzida pela forma de reação individual à apresentação pública e material de obras poéticas.

O legado de Aristóteles às teorias da recepção transcende, assim, a aceitação de que decorre da resposta do auditório - resposta definida de modo coletivo, mas experimentada de maneira pessoal - a consolidação da poesia enquanto sistema dotado de características próprias, aptas a serem descritas por meio de instrumentos específicos, como a Poética e a Retórica à época daquele filósofo, ou, desde o século XIX, a Teoria da Literatura e a História da Literatura. Ele inclui ainda a admissão de que a recepção supõe fatores materiais, de ordem sensorial, de um lado, já que incide em reação emocional, e de ordem tecnológica, de outro, já que se relaciona aos suportes - a voz ou a escrita - que acompanham os processos de intercâmbio da obra com o público. As teorias da recepção, que, após as manifestações da linguagem verbal terem adotado a escrita enquanto seu principal veículo de transmissão, mesclam-se a teorias da leitura, alternam-se entre essas posições, privilegiando, de uma parte, o exame das relaçôes entre a obra e seu destinatário, encarado individual ou coletivamente, e, de outra, o estudo dos objetos impressos, que circulam ou não como literatura e que passam com transformações históricas, ideológicas e comportamentais, desde a invenção dos meios mecânicos de reprodução tipográfica. 
As teorias da recepção fundamentam-se em um pressuposto quase tautológico - o de que as obras são objeto de algum tipo de acolhimento. O mais usual deles é a leitura, mas essa dependeu, primeiramente, de a escrita transformar-se no veículo preferencial de comunicação de textos poéticos ou não. Medidas coletivas determinaram essa eleição, sendo a primeira delas a difusão do alfabeto, o que ocorre, no Oriente, entre sumérios, babilônios, egípcios, hebreus e fenícios, e, no Ocidente, entre os gregos. A segunda dessas medidas foi a eleição de uma instituição para a difusão da escrita a escola. Itamar Even-Zohar identifica, já entre os sumérios, a presença de escolas - $\hat{e}$-dubba - destinadas à aprendizagem de textos considerados canônicos. ${ }^{*}$ Aquelas, porém, tinham vínculos com a religião e eram dominadas por sacerdotes, ao contrário do que ocorreu entre os gregos, que, a partir do século $\mathrm{V}$ a.C., estimularam o conhecimento da língua e da poesia para que os cidadãos dispusessem de melhores recursos retóricos para defender seus direitos, inclusive o de propriedade, como lembra Roland Barthes."

A secularização do ensino precede a da poesia, detectada na Poética, de Aristóteles, e constitui condição básica para a expansão da leitura, ainda que, no mundo antigo, ficasse restrita às classes elevadas. Seu exercício não impediu a circulação oral da poesia, de que dão testemunhos a popularidade do teatro e a prática de declamações públicas, reproduzidas em cenas dos diálogos de Platão. Porém, a leitura individual era igualmente usual, como sugerem as Heróidas, de Ovídio, ainda que provavelmente em voz alta, já que a leitura silenciosa parece ter-se difundido somente a partir do século III d.C.*

A expansão da leitura suscitou, assim, representações que reproduzem sua prática, que se integra às diferentes atividades de seus usuários: Fedro lê para Sócrates o discurso de Lísias que o empolgou, sinalizando sua participação na vida política de Atenas; ${ }^{*}$ Teseu lê a carta em que Fedra, antes de se suicidar, acusa seu enteado, Hipólito, de assédio sexual; a mesma Fedra, na carta que lhe atribui Ovídio, confessa a Hipólito o amor proibido que nutre pelo rapaz. Em nenhum desses casos, a leitura é objeto de julgamento, seja o encomiástico, seja o condenatório. Obras bem posteriores, como Tirant lo Blanc, do catalão Joanot Martorell, publicada no final do século XV, quando a imprensa já se difundia na Península Ibérica, mantêm esse comportamento: tanto o protagonista, quanto o
(EVEN-ZOHAR, Itamar "La literatura como bienes y como herramientas". Em: VILLANUEVA, Dario; MONEGAL, Antonio; BOU, Enric (org.). Sin fronteras: ensayos de literatura compa rada em homenaje a Claudio Guillen. Madri: Castalia 1999: 29.)

"(BARTHES, Roland. Investigaciones retóricas I. La antigua retórica. Ayadamemoria. Buenos Ayres: Tiempo Contemporaneo, 1974.)

"(BLANCK, Horst. Das Buch in der Antike. München: Beck, 1992.) (FISCHER, Steven Roger. História da leitura. Trad. de Cláudia Freire. São Paulo: Editora UNESP, 2006.)

• (PLATÃO. Fedro. Trad. de Jorge Paleikat. Rio de Janeiro: Tecnoprint, 1966.)

" (EURÍPEDES. Hipólito. Trad. de Bernardina de Sousa Oliveira. Coimbra: Instituto Nacional de Investigação Científica; Centro de Estudos Clássicos e Humanísticos da Universidade de Coimbra, 1979.)

"(OVIDE. Les Héroïdes. Trad. de Émile Ripert. Paris: Garnier, 1930.) 
(MARTORELL, Joanot. Tirant lo Blanc. Trad. de Cláudio Giordano. São Paulo: Atelier, 2004.)

-(DIAS, J. S. da Silva. "O primeiro rol de livros proibidos". Biblos. Revista da Faculdade de Letras. Universidade de Coimbra. V. XXXIX, 1963: 232.) (SÁ, Artur Moreira de. Índice dos livros proibidos em Portugal no século XVI. Lisboa: Instituto Nacional de Investigação Científica, 1983.)

- (CERVANTES, Miguel de. Don Quixote de la Mancha. Edição de Florencio Sevilla Arroyo e Antonio Rey Hazas. Madrid: Alianza, 1996. v. 1:38.)
Sr. de Varoic, personagem da parte inicial do romance, mostram-se leitores assíduos, que discutem as matérias literárias apreciadas por eles; ${ }^{*}$ contudo, não se observam na obra juízos, éticos ou políticos, diante dessa atitude incorporada à rotina das figuras ficcionais.

Esse posicionamento mudou a partir do século XVI, após a invenção e expansão da tipografia. A utilização da prensa mecânica propiciou a produção de livros em nível empresarial, que requeriam consumo em grande escala. Os primeiros best-sellers apareceram nas décadas iniciais do século XVI, que contavam com um público instalado nas cidades que cresciam em população e riqueza. Esse primeiro surto industrial garantiu o aparecimento de novos gêneros, como o romance e a narrativa de viagens, e o encorpamento de gêneros já existentes, como o romance de cavalaria, que tem no mencionado Tirant lo Blanc uma de suas manifestações.

A partir de então, a relação com os livros e, em especial, com a leitura deixou de ser neutra, como se mostrava até então, tornando-se motivo de julgamento severo e discriminação. Uma das mais antigas reaçôes à expansão da imprensa foi a publicação, em 1564 , pelo papa Pio IV, do Index Librorum Prohibitorum; antes dele, em 1547, em Portugal, o cardeal D. Henrique, Inquisidor Geral do Reino, já tinha proibido um rol de livros, que incluía mesmo as Sagradas Escrituras, se publicadas em língua vulgar. Essas ações tinham endereço certo: o crescente público leitor, consumidor de obras indesejadas, como o Elogio da loucura, do pensador independente Erasmo de Rotterdam, cujas sucessivas edições incomodavam os padres conservadores da Igreja.

Boas e más leituras são matéria da celebrada discussão entre o cura e o barbeiro, no capítulo VI da primeira parte de Don Quixote de la Mancha, de Miguel de Cervantes, obra em que aparece outro efeito colateral do fenômeno industrial derivado da invenção da tipografia: as mudanças interiores pelas quais pode passar um indivíduo que se devota em excesso e indiscriminadamente ao consumo de obras literárias. O protagonista do romance é o "fidalgo, [que] nos intervalos em que estava ocioso - que eram os mais do ano - se dava a ler livros de cavalaria, com tanta afeição e gosto, que se esqueceu quase completamente do exercício da caça, e até da administração dos seus bens; e a tanto chegou sua curiosidade e desatino neste ponto, que vendeu muitas courelas de semeadura para comprar livros de cavalarias que ler; com o que juntou em casa quantos pôde apanhar daquele gênero." Tais leituras levam "o 
pobre cavaleiro" a perder o "juízo", efeito indesejado e razão suficiente para condenar a literatura ao fogo, como faz a família de D. Quixote, com a cumplicidade dos mencionados cura e barbeiro.

A leitura, doravante, é matéria freqüente de representação por parte da literatura, que assume posição freqüentemente ambígua em relação aos efeitos que pode provocar, poucos deles entendidos de modo favorável, como fez Aristóteles a propósito da catarse. Como sabem os leitores de Madame Bovary, de Gustave Flaubert, de O primo Basílio, de Eça de Queirós, ou de $A$ normalista, de Adolfo Caminha, os livros podem desencaminhar ingênuas donzelas, subverter a ordem e ameaçar os valores patriarcais. Essa temática atravessa a história da literatura, mas não se limita à representação que os livros fazem de si mesmos. A atitude censora migra da ficção para a ciência, quando a expansão da indústria do livro gera, a partir do século XIX, a literatura de massa.

\section{Livros do bem, livros do mal}

Se uma revolução tecnológica - a utilização dos tipos móveis, atribuída a Gutenberg - facultou a expansão da indústria tipográfica e a consolidação do livro como suporte preferencial da escrita, outras mudanças de similar teor permitiram a expansão dos meios de comunicação: a invenção da rotativa, que acelerou a impressão das folhas, propiciando a produção diária de periódicos; o aperfeiçoamento da qualidade do papel e seu barateamento; o aparecimento da máquina de escrever. Os novos mecanismos ajudavam a diminuir a distância temporal entre a escrita de um texto e sua impressão, incrementando o aparecimento de novos títulos. Por sua vez, o público leitor aumentou quantitativamente, em decorrência da migração do campo para os grandes centros industriais, do fortalecimento da burguesia urbana e da difusão da escolarização. A equação estabeleceu-se de imediato: maior audiência igual a maior oferta; o crescimento dessa oferta possibilitou, de uma parte, a profissionalização dos escritores; de outra, porém, esses precisaram se adaptar às exigências tanto dos empresários do livro, interessados na lucratividade de suas fábricas, quanto dos consumidores, carentes de uma literatura que se adequasse a seu gosto e à sua formação.

Assim como a revolução tecnológica do século XV suscitou o aparecimento de novos gêneros e a reciclagem dos antigos modos de expressão, as modificações do século XIX ocasionaram o surgimen- 
- (CHARTIER, Roger. Lectures et lecteurs dans la France d'Ancien Régime. Paris: Seuil, 1987.) (SCHENDA, Rudolf. Die Lesestoffe der kleinen Leute. Studien zur populären Literatur im 19. und 20. Jahrhundert. München: Beck, 1976.) (SCHENDA, Rudolf. Volk ohne Buch. Studien zur Sozialgeschichte der populären Lesestoffe. München: DTV, 1977.)

"(SCHÜCKING, L. L. The Sociology of Literary Taste. Chicago: The University of Chicago Press, 1966.)

'(LEAVIS, Q. D. The Fiction and the Reading Public. London: Pelican, 1979.)

(HOGGART, Richard. The Uses of Literacy. London: Pelican, 1977.)

- (HUYSSEN, Andreas. After the great divide. Modernism, Mass Culture, Postmodernism. Bloomington and Indianapolis: Indiana University Press, 1986.) to de formas específicas de comunicação. A imprensa, agora diária, introduziu o folhetim, que migrou das folhas dos jornais para as páginas dos livros, processo praticado dos dois lados do oceano Atlântico, como testemunham as criações literárias do francês Alexandre Dumas e dos brasileiros José de Alencar e Machado de Assis.

$O$ folhetim gerou vários subgêneros do romance e contou com a adesão do público leitor, especialmente o das cidades, já que os leitores do campo tinham suas próprias preferências, conforme indicam pesquisas sobre a literatura de cordel e a Bibliothèque Bleue, de larga circulação na Europa do século XVIII.* Contudo, não alcançou as boas graças da elite intelectual, constituída, de uma parte, por artistas descontentes com o sucesso de seus confrades, de outra, pelos pesquisadores encastelados na universidade. Os primeiros procuraram renovar a arte da narrativa, investindo em formas inusitadas de expressão, para desenhar seu espaço exclusivo de criação e garantir a identidade e a particularidade de sua obra. Os segundos instituíram a sociologia da leitura, cujas primeiras manifestações aparecem nas primeiras décadas do século XX.

Um dos primeiros estudiosos dos fenômenos coletivos vinculados à leitura é o alemão L. L. Schücking, cuja obra, A sociologia do gosto literário, de 1923, visa interpretar as preferências do público, entendido esse como um elemento ativo que interfere não apenas do prestígio de um texto, mas também em sua criação. ${ }^{*}$ Schücking adota um olhar desarmado perante as obras que fazem sucesso junto aos consumidores de leitura, definidos a partir de seu gosto; mas, na década de 30, quando seu livro foi traduzido na Inglaterra, sua perspectiva foi substituída por uma visão preconceituosa diante dos objetos que as massas trabalhadoras elegem como leitura. Verifica-se tal posicionamento em A ficção e o público leitor, de 1931, obra de Q. D. Leavis, que reconhece a existência dos novos grupos sociais, ao mesmo tempo em que rebaixa suas escolhas. * Richard Hoggart, em Os usos da alfabetização, de 1957, não diverge muito de Leavis ao verificar a notável expansão do processo de letramento entre os segmentos mais pobres da população inglesa, fato, contudo, que não o gratifica, já que os beneficiados desse fenômeno se dirigem ao consumo da literatura de massa, de fácil absorção, mas de pouca durabilidade e pequena importância cultural.

A segunda metade do século XX posicionou-se de modo diferente diante dessas questões. Diante do esgotamento do que Andreas Huyssen chamou o "great divide", que acentua a separação 
entre a alta cultura, elitizada e difícil, e a cultura popular, massificada e alienante, denúncia de que são porta-vozes pensadores como Theodor W. Adorno, foi preciso rever os pressupostos adotados e buscar novas vias de investigação. A Sociologia da Leitura não desaparece, mas passa a incluir a História da Leitura, para a qual é importante localizar as obras efetivamente publicadas, lidas e consumidas nos diferentes períodos da História.

O novo viés é decisivo para quem se posiciona nesse campo intelectual, pois o great divide colocava, de um lado, obras canônicas do passado e, de outro, a literatura de massa da atualidade, sem evidenciar que aquelas correspondiam a um pequeno percentual do que efetivamente circulou em tempos idos. Autores como Robert Escarpit, ${ }^{*}$ entre os anos 50 e 70, e Robert Darnton ${ }^{*}$ ou Roger Chartier, a partir dos anos 80 , embora assumam perspectivas distintas do ponto de vista teórico, evidenciam que o sistema literário incluiu muito mais títulos que a história da literatura registra. Em um intenso trabalho de recuperação de fontes, esses pesquisadores complementam o universo de leitura de diferentes camadas sociais, zonas geográficas e gêneros, para esclarecer em que medida a literatura apresenta horizontes plurais de recepção e consumo, diante dos quais todo julgamento pode ser precipitado, se calcado unicamente em critérios contemporâneos.

A Sociologia da Leitura, quando associada à perspectiva histórica, dimensiona o campo literário em termos que extravasam o foco adotado pela Teoria da Literatura, fecundando o diálogo com a pesquisa com fontes primárias, que alarga as fronteiras das duas áreas de conhecimento.

\section{A Teoria da Literatura reage}

Nas oportunidades em que historiou a trajetória da Estética da Recepção, Hans Robert Jauss atribui à conferência com que abriu o semestre de verão na Universidade de Constança a condição de episódio fundador da vertente de investigação de que é também o principal representante. Em 13 de abril de 1967, ele expôs suas idéias em resposta à pergunta colocada no título da conferência, "O que é e com que fim se estuda História da Literatura?", para estabelecer as bases de uma teoria em que procura colocar o leitor na posição de figura central da pesquisa literária.

Jauss, naquele que veio a constituir o texto seminal da Estética da Recepção, publicado com o título de "A História da Literatura
(ADORNO, Theodor W. Horkheimer, Max. Dialética do esclarecimento. Trad. de Guido Antônio de Almeida. São Paulo: Jorge Zahar, 1985.)

"(ESCARPIT, Robert. Le littéraire et le social. Elements pour une sociologie de la littérature. Paris: Flammarion, 1970.)

"(DARNTON, Robert. The Literary Underground of the Old Régime. Cambridge and London: Harvard University Press, 1982.) (DARNTON, Robert. The Great Cat Massacre and Other Episodes in French Cultural History. New York: Vintage Books, 1985.) (DARNTON, Robert Os best-sellers proibidos da França pré-revolucionária. São Paulo: Companhia das Letras, 1998.)

* (CHARTIER, Roger. A ordem dos livros: leitores, autores e bibliotecas na Europa entre os séculos XIV e XVIII. Trad. de Mary del Priori. Brasília, Universidade de Brasília, 1994.) 
(JAUSS, Hans-Robert. La literatura como provocación. Trad. de Juan Godo Costa. Barcelona: Península, 1976: 168.) como provocação", ataca várias frentes, para delimitar as fronteiras de seu pensamento: polemiza concepções vigentes de História da Literatura; questiona a Sociologia da Literatura, de orientação marxista e praticada sobretudo por Georg Lukács; rejeita o Estruturalismo em voga nos anos 60 do século XX, embora absorva alguns dos conceitos propostos por lingüistas como Ferdinand de Saussure e filósofos como Jan Mukarovski. Seu objetivo principal é recuperar a historicidade da literatura, descartada por essas vertentes, meta possibilitada pela valorização da ação do leitor, responsável pela permanente atualização das obras literárias do passado.

A Estética da Recepção assume a perspectiva do leitor, portanto, conforme sua denominação sugere, ao considerar que é ele quem garante a historicidade das obras literárias. Em decorrência do fato de o leitor não deixar de consumir criações artísticas de outros períodos, essas se atualizam permanentemente. Conforme Jauss anota, uma obra "só se converte em acontecimento literário para seu leitor"; portanto, é esse sujeito que afiança a vitalidade e continuidade do processo literário.

Jauss considera que, entre a obra e o leitor, estabelece-se uma relação dialógica. Essa relação, por sua vez, não é fixa, já que, de um lado, as leituras diferem a cada época, de outro, o leitor interage com a obra a partir de suas experiências anteriores, isto é, ele carrega consigo uma bagagem cultural de que não pode abrir mão e que interfere na recepção de uma criação literária particular. Assim, quando se depara com um romance como Dom Casmurro, de Machado de Assis, ele sabe de antemão que esse romance é um clássico da literatura brasileira, que foi escrito após Memórias póstumas de Brás Cubas e antes de Esaú e Jacó, que influenciou autores como Graciliano Ramos, Fernando Sabino e Ana Maria Machado, por exemplo; o romance, portanto, vem carregado de uma história de leituras que se agregam a ele. Da sua parte, esse leitor, independentemente de sua formação ou profissão, carrega também sua história de leituras, construída a partir de sua relação com a literatura e com outras formas de textos transmitidos pela escrita. Assim, o diálogo entre a obra e o leitor coloca frente a frente duas histórias, a partir da qual se estabelece uma troca: o leitor incorpora a leitura de Dom Casmurro, com todos os elementos que o romance traz consigo, à sua própria história; Dom Casmurro, por sua vez, agrega à sua identidade de obra literária a leitura desse leitor, que fará uma decodificação específica do texto a partir de sua matriz pessoal e cultural. 
Nenhum leitor fica imune às obras que consome; essas, da sua parte, não são indiferentes às leituras que desencadeiam. Portanto, para Jauss, o leitor constitui um fator ativo que interfere no processo como a literatura circula na sociedade. Só que a ação do leitor não é individualista; nem cada leitor age de modo absolutamente singular. Segundo Jauss, as épocas ou as sociedades constituem horizontes de expectativa dentro dos quais as obras se situam. Essas expectativas advêm da "compreensão prévia do gênero, da forma e da temática das obras anteriormente conhecidas e da oposição entre linguagem poética e linguagem prática."*

Assim, as obras, quando aparecem, não caem em um vazio: ao serem publicadas, deparam-se com códigos vigentes, normas estéticas e sociais, formas de comunicação consideradas cultas ou populares, preconceitos e ideologias dominantes. Esses dados determinam o "saber prévio" dos leitores, que condiciona a recepção do texto em certa época ou dentro de um grupo social. O "saber prévio" é coletivo e incide sobre as possibilidades de decifração de uma obra, sugerindo que os leitores atuam de modo coeso. Na concepção de Jauss, o leitor é um fator preponderante do sistema literário, determinando os modos de acolhimento, valorização e circulação das obras; sua ação não é, porém, idiossincrática ou singular, pelo contrário, corresponde aos efeitos de um comportamento comum às pessoas de um dado agrupamento social. Por essa razão, esses efeitos podem ser definidos e estudados, equivalendo à história da recepção de uma certa obra.

O leitor, portanto, coincide com o horizonte de recepção ou acolhimento de uma obra. Essa, por sua vez, destaca-se quando não se equipara a esse horizonte, pois, se o fizesse, nem seria notada. Com efeito, cada obra procura se particularizar diante do universo para o qual se apresenta, particularização que se evidencia quando ela rompe com os códigos e as normas predominantes. Assim, ela estabelece um intervalo entre o que se espera e o que se realiza, a que Jauss denomina "distância estética".

Pode-se perceber que Hans Robert Jauss endossa a tese das várias vertentes modernistas que encontraram sua configuração teórica no pensamento dos formalistas russos e dos estruturalistas tchecos, bem como na Sociologia da Literatura, quando expressa por filósofos como Georg Lukács, Walter Benjamin e Theodor W. Adorno. Também para o pesquisador da Estética da Recepção, a identidade e a qualidade de uma obra dependem de sua propensão à ruptura, à inovação, ao desafio às normas vigentes. 
Esse posicionamento, por sua vez, requer um esclarecimento relativamente às suas teses sobre a relação dialógica entre a obra e o leitor. Se a obra não aceita o horizonte dentro do qual emerge, como interage com o leitor? Pode-se concluir que a relação é tensa e pouco amistosa, já que a obra de arte desafia não apenas preconceitos e a ideologia dominante, mas o código de conduta, as normas lingüísticas, as formas de expressão que o leitor emprega. Uma obra que se deseje marcante precisa suplantar limites, incluindo-se aí os parâmetros por meio dos quais o leitor rege sua vida.

Veja-se o caso do romance Dom Casmurro, de Machado de Assis. Por meio da narrativa em primeira pessoa, Bento Santiago rememora sua adolescência, quando era apaixonado pela moça da casa ao lado, Capitu, e estava impedido de namorá-la, mais ainda de desposá-la, porque sua mãe tinha prometido torná-lo padre. O garoto não se sente vocacionado para a carreira eclesiástica, mas não se considera capaz de desafiar a ordem materna. Acaba por pedir a ajuda a José Dias, um agregado que residia em sua casa, mas é Escobar, jovem que conhecera no seminário enquanto fazia sua formação religiosa, quem encontra a solução para o impasse. Após o matrimônio, nasce Ezequiel, mas Bento desconfia que a mulher o traiu e que o menino não é seu filho, mas fruto do affaire entre sua esposa e Escobar. Convicto do adultério, ele afasta-se de Capitu, levando-a para a Europa, onde ela permanece até morrer.

A narrativa de Machado de Assis pode ser examinada desde várias perspectivas, que apontam para um elemento comum: a profunda decepção de Bento Santiago, que investiu sua existência em uma relação amorosa e viu o projeto fracassar. Sua trajetória contradiz o padrão épico: ele não é a pessoa talhada para resolver os próprios problemas, dependendo invariavelmente de um adjuvante: sua mãe, José Dias, Capitu, por último, Escobar. Além disso, suas açôes estão fadadas ao insucesso, haja vista a traição de que é alvo, levada a cabo por duas pessoas que lhe eram caras, a esposa e o melhor amigo. Ciente de sua incompetência nata, Bento Santiago refugia-se em sua memória, narrando o que lhe aconteceu e justificando a melancolia com que encerra o relato.

Dom Casmurro não é o primeiro romance a tratar do adultério, tema que foi matéria de dois importantes romances da segunda metade do século XIX conhecidos pelo público brasileiro à época em que o livro de Machado de Assis é publicado: Madame Bovary, de Gustave Flaubert, e O primo Basílio, de Eça de Queirós. 
Nos dois casos, trata-se de histórias de esposas que traem os maridos, em parte, porque sonham com amantes heróicos como os das novelas que leram, em parte, porque seus próprios matrimônios as decepcionam. Na literatura brasileira, o tema tinha sido matéria de romances folhetinescos, como $O$ marido da adúltera, de Lúcio de Mendonça, de 1882, ou naturalistas, como O hóspede, de Pardal Mallet, de 1887. Também essas obras privilegiam o ângulo da esposa insatisfeita com o casamento, que busca na aventura extraconjugal uma compensação para o tédio doméstico.

Pode-se verificar em que medida Machado inova o tema: em primeiro lugar, ele abandona o clichê da mulher simultaneamente romântica e entediada, mesmo porque o leitor, por acompanhar a narrativa desde o foco de Bento Santiago, não tem acesso à interioridade de Capitu. Esse é, pois, o segundo elemento inovador proposto por Machado: a perspectiva é dada pelo marido traído, que, porém, nunca domina inteiramente a situação. Assim como não consegue conduzir sua vida de modo independente, permitindo que outros resolvam seus problemas, ele não tem sucesso ao tentar controlar a narração, razão porque o leitor não fica plenamente convencido do adultério de Capitu. O narrador não é, pois, inteiramente confiável, já que Machado semeia ao longo do texto uma série de dúvidas e incertezas, que minam a convicção que Bento Santiago procura transmitir.

O romance acaba por abalar as certezas que se poderia ter em relação a seu assunto, já que o juízo relativamente à infidelidade conjugal de Capitu fica em suspenso. Por essa atitude, pode-se medir a coragem de Machado de Assis ao tratar a questão; afinal, seus precursores, entre os quais os renomados Gustave Flaubert e Eça de Queirós, não titubearam ao condenar as esposas pérfidas, pois essas prevaricam aos olhos do leitor. Além disso, a sociedade brasileira da época de Machado era fortemente machista, e a mera suspeita de adultério era motivo suficiente para um marido condenar a esposa.

Evidencia-se o modo como o escritor brasileiro aceita compor um romance na contracorrente das ideologias vigentes e das tendências literárias dominantes. Ao romper com os paradigmas literários e sociais relativos ao adultério e à condição da mulher na sociedade brasileira, ele produz uma obra revolucionária que acabou por se converter em um clássico respeitado pela história da literatura brasileira.

É sob esse aspecto que o romance testemunha a operação que Jauss designa como "distância estética", já que se assume conside- 
• JAUSS, Hans Robert. "Petite apologie de l'expérience esthétique". Em: Pour une esthétique de la réception. Paris: Gallimard, 1978.) rável intervalo entre o que os escritores faziam e seus conterrâneos pensavam, de um lado, e sua própria obra, de outro. Por causa dessa qualidade, esta se mostra emancipatória, já que expõe uma realidade tal como a conhecemos, com seus valores e preconceitos, para que possamos pensar que ela não deve ser assim. Explica Jauss:

A experiência da leitura pode liberá-lo [o leitor] de adaptaçóes, prejuízos e constrangimentos de sua vida prática, obrigando-o a uma nova percepção das coisas. O horizonte de expectativas da literatura distingue-se do horizonte de expectativas da vida prática histórica, porque não só conserva experiências passadas, mas também antecipa a possibilidade irrealizada, alarga o campo limitado do comportamento social a novos desejos, aspiraçōes e objetivos e com isso abre caminho à experiência futura.

Por ser emancipatória, a literatura pode colaborar para que leitor se libere de seus prejuízos e limitações. Portanto, a criação inovadora pode efetivamente contrariar expectativas do leitor, quando essas estão vinculadas a preconceitos e valores a serem ultrapassados. Porém, o envolvimento por meio da leitura - envolvimento que, segundo Jauss, contém um componente catártico* - leva o leitor a participar do projeto liberador da obra. Assim, o leitor configura-se como parceiro do texto, concretizando o processo dialógico que fundamenta a leitura.

A Estética da Recepção aposta na ação do leitor, pois dele depende a concretização do projeto de emancipação que justifica a existência das criaçôes literárias. E, ao registrar seu débito para com Aristóteles, completa o circuito histórico dentro do qual se localizam as pesquisas que privilegiam a recepção e a leitura no âmbito da Ciência da Literatura. 


\section{Regina Zilberman}

Doutora em Romanística pela Universidade de Heidelberg, Alemanha; professora Colaboradora no Programa de Pós-Graduação em Letras, da UFRGS; professora das Faculdades Porto-Alegrenses; pesquisadora 1A, CNPq. Autora de Estética da recepção e História da literatura e Fim do livro, fim dos leitores?, entre outros.

\section{Resumo}

Desde a Poética, de Aristóteles, a recepção das obras literárias constitui matéria de investigação teórica, sociológica e histórica, cujas vertentes mais significativas são examinadas neste estudo.
Abstract
Since Aristotle's Poetics, the re-

\section{Résumé}
ception of literary works has been matter of theoretical, socio- logical and historical researches. Their more significant tenden- cies are examined in this article.
Depuis la Poétique, d'Aristote, la réception des œuvres littérai- res constitue le sujet d'une in- vestigation théorique, sociolo- gique et historique dont nous examinons ici les aspects les plus importants.

Palavras-chave: recepção; leitura; leitor.

Key words: reception; reading; reader.

Mots-clés: réception; lecture; lecteur. 